\title{
INCENTIVES TO SETTLE UNDER \\ JOINT AND SEVERAL LIABILITY: \\ AN EMPIRICAL ANALYSIS OF \\ SUPERFUND LITIGATION
}

\author{
Howard F. Chang \\ Hilary Sigman
}

Working Paper 7096

http://www.nber.org/papers/w7096

\author{
NATIONAL BUREAU OF ECONOMIC RESEARCH \\ 1050 Massachusetts Avenue \\ Cambridge, MA 02138 \\ April 1999
}

We wish to thank Dan Kessler, Dan Klerman, and Lewis Kornhauser for helpful comments. This research was supported in part by grant R82-2368 from the Office of Exploratory Research of the U.S. Environmental Protection Agency. The views expressed herein are those of the authors and do not necessarily reflect the views of the National Bureau of Economic Research.

( 1999 by Howard F. Chang and Hilary Sigman. All rights reserved. Short sections of text, not to exceed two paragraphs, may be quoted without explicit permission provided that full credit, including ${ }^{(}$notice, is given to the source. 
Incentives to Settle Under Joint and Several Liability:

An Empirical Analysis of Superfund Litigation

Howard F. Chang and Hilary Sigman

NBER Working Paper No. 7096

April 1999

JEL No. K41, Q28

\section{ABSTRACT}

Congress may soon restrict joint and several liability for cleanup of contaminated sites under Superfund. We explore whether this change would discourage settlements and is therefore likely to increase the program's already high litigation costs. Recent theoretical research by Kornhauser and Revesz finds that joint and several liability may either encourage or discourage settlement, depending upon the correlation of outcomes at trial across defendants. We extend their twodefendant model to a richer framework with $N$ defendants. This extension allows us to test the theoretical model empirically using data on Superfund litigation. We find that joint and several liability does not discourage settlements and may even encourage them. Our results support the model's predictions about the effects of several variables, such as the degree of correlation in trial outcomes.

Howard F. Chang

University of Pennsylvania Law School 3400 Chestnut Street

Philadelphia, PA 19104-6204

hchang@law.upenn.edu
Hilary Sigman

Department of Economics

Rutgers University

75 Hamilton Street

New Brunswick, NJ 08901-1248

and NBER

hsigman@econ.rutgers.edu 
Courts have interpreted Superfund, formally the Comprehensive Environmental Response, Compensation, and Liability Act (CERCLA) ${ }^{1}$ to impose joint and several liability on parties associated with contaminated sites. Joint and several liability allows the plaintiff to recover full damages from any defendant in a multidefendant case, regardless of the defendant's share of liability for the damages. This liability rule is controversial. All of the major proposals for Congressional reauthorization of Superfund would restrict joint and several liability (Reisch, 1998).

These changes to the liability rules may reduce the incentives for defendants to settle, worsening the already large transactions costs associated with Superfund. In 1985, the Reagan administration argued that Superfund's joint and several liability would encourage defendants to settle. ${ }^{2}$ Early theoretical work on joint and several liability supported this claim (Easterbrook et al., 1980; Polinsky and Shavell, 1981). However, recent research indicates that the effect of joint and several liability on multidefendant settlements depends on the degree to which the plaintiff's probabilities of success at trial are correlated across the defendants. Lewis Kornhauser and Richard Revesz $(1993,1994)$ present a formal model in which joint and several liability encourages settlements if these probabilities are sufficiently correlated but discourages settlements if they are independent. Kornhauser and Revesz (1995a) have applied their theoretical analysis to joint and several liability under Superfund, seeking to inform the Superfund reauthorization debates. They conclude that theory alone cannot resolve the debates over the effects of joint and several liability.

This paper extends the Kornhauser and Revesz model to derive several hypotheses, which we test using data on settlements between the Environmental Protection Agency (EPA) and defendants under the Superfund. The empirical analysis considers both the choice of settlement over litigation and the time between filing of the case and settlement. By examining

\footnotetext{
${ }^{1} 42$ USC $\S \S 9601-9675$.

${ }^{2}$ See, e.g., Superfund Reauthorization, Judicial and Legal Issues: Oversight Hearings Before the Subcomm. on Admin. Law and Gov't Relations of the House Comm. on the Judiciary, 99th Cong. 5-6 (1985) (statement of Lee Thomas, EPA Administrator); id. at 45 (statement of F. Henry Habicht II, Assistant Attorney General, Land and Natural Resources Division); Superfund Improvement Act of 1985: Hearings on S. 51 Before the Senate Comm. on the Judiciary, 99th Cong. 18, 22 (1985) (statement of Lee Thomas, EPA Administrator).
} 
these outcomes, we seek to discover whether joint and several liability under Superfund tends to encourage or discourage settlement. The results shed light on the controversy over Superfund's liability rules. They also provide an empirical test of current theoretical models of parties' behavior under joint and several liability.

The empirical results do not support the view that joint and several liability discourages settlement under Superfund. Indeed, the results are consistent with a settlement-promoting effect from joint and several liability. In addition, the results support many of the predictions of the theory. For example, we find that the likelihood of settlement rather than litigation grows with the number of defendants. We also test the effects of two measures of the likely degree of correlation in trial outcomes among defendants. Defendants appear to settle more frequently or more rapidly when this correlation is high, consistent with the theoretical predictions.

The paper begins with a discussion of the previous theoretical literature on joint and several liability. The second section presents our theoretical model of settlement under joint and several liability. The third section introduces the data that we use to test this model. The fourth section presents econometric estimates for two sets of equations. One set of equations analyzes the determinants of settlement as opposed to litigation. A second set of equations analyzes time to settlement, using a hazard rate model. A fifth section concludes with implications for the Superfund debate.

\section{Previous Literature}

Kornhauser and Revesz present a model of a single plaintiff bringing suit against two defendants. They assume complete information, so that each party has the same beliefs regarding the plaintiff's probability of success at trial, the amount that would be awarded if the plaintiff prevails, and the litigation costs of each party. They consider the case in which each party is risk-neutral and infinitely solvent, and litigation costs are zero. The plaintiff makes a settlement offer to each defendant. The defendants then decide simultaneously and nonco- 
operatively whether to accept these offers. The plaintiff then litigates against any nonsettling defendants.

Under nonjoint (several only) liability, the plaintiff's claim against each defendant is equal to that defendant's share of the total liability. In this case, the parties are indifferent between litigation and settlement, whether the plaintiff's probabilities of success against the defendants are correlated or independent. Each party would be willing to settle for the expected value of the outcome at trial if all were to litigate instead.

Under joint and several liability, if the plaintiff prevails against both defendants, then the court apportions the damages between the defendants according to their relative shares of the liability. Under an unconditional pro tanto setoff rule, if only one defendant accepts the settlement offer, then the court reduces the plaintiff's claim against the nonsettling defendant by the amount of the settlement, without inquiring into whether the settling defendant was liable. ${ }^{3}$ CERCLA, for example, imposes joint and several liability for the cost of cleaning up hazardous waste sites on responsible parties (generators and transporters of hazardous wastes and owners and certain prior owners of hazardous waste sites) and applies an unconditional pro tanto rule in the event of partial settlement. ${ }^{4}$

If the probability of success against each defendant is independent, then Kornhauser and Revesz show that joint and several liability (with an unconditional pro tanto rule) discourages settlement. Specifically, under these circumstances the plaintiff will prefer litigation over any settlement on terms acceptable to one or both defendants. If the probabilities of success against the defendants are instead perfectly correlated, then joint and several liability encourages settlement. ${ }^{5}$ Thus, Kornhauser and Revesz show that the effect of joint

\footnotetext{
${ }^{3}$ Klerman (1996) shows that the tendency for joint and several liability to inhibit settlement depends on the assumption that the setoff is unconditional.

${ }^{4}$ See 42 USC $\S \S 9607(\mathrm{a}), 9613(\mathrm{f})(2)$.

${ }^{5}$ Suppose the defendants would share liability equally if they both litigate and then lose at trial. Under these circumstances the plaintiff will strictly prefer settlement with both defendants over litigation. Kornhauser and Revesz derive more ambiguous results when the shares of the two defendants are unequal: if these shares are sufficiently different, then the plaintiff will prefer to settle with one defendant and litigate against the other. This result, however, seems to be an artifact of their assumptions regarding the bargaining game. For example, if the plaintiff can make settlement offers to the defendants in sequence rather than simultaneously, then the plaintiff would prefer settlement with both defendants over litigation.
} 
and several liability upon settlement depends upon the degree to which the probabilities of success against the defendants are correlated. ${ }^{6}$ If defendants can cooperate in settlement negotiations, however, then the effects of joint and several liability upon settlement disappear. $^{7}$

We extend the Kornhauser-Revesz model to the more complex case of $N$ defendants to see how the Kornhauser-Revesz results generalize. With more than two defendants, it becomes possible for the probability of success at trial for one defendant to be correlated with the corresponding probability for some defendants but not with the probability for other defendants. Our extension allows for this more complex pattern of correlations and enables us to generate predictions that we can test using data on Superfund settlements with large groups of defendants. In particular, we generate comparative statics results regarding the effect of the number of defendants and the correlation among trial outcomes upon the likelihood at settlement. We also extend the Kornhauser-Revesz model by developing an explicit model of the likelihood of settlement that includes a role for not only litigation costs but also pessimism or optimism regarding the outcome at trial. These extensions prove to be important and produce some surprising results: the effect of some parameters on the likelihood of settlement can depend on whether differences in litigation costs or in pessimism account for differences in settlement outcomes. Our extensions enable us to test whether joint and several liability (with the unconditional pro tanto rule) has the expected effects on settlements and if so, whether it on balance encourages or discourages settlements in the Superfund context.

\footnotetext{
${ }^{6}$ Prior analysis of multidefendant settlements focused on the case of perfect correlation. See Easterbrook et al. (1980) and Polinsky and Shavell (1981).

${ }^{7}$ Furthermore, Donohue (1994) shows that by making settlement offers that are contingent upon acceptance by all defendants, a plaintiff could obtain the same outcome that perfect cooperation among the defendants would produce.
} 


\section{Model}

Suppose that a single plaintiff brings suit against $N$ defendants, where $N$ is an integer and $N \geq 1$. Suppose that the defendants would share liability equally if they litigate and lose at trial. Normalize the amount of damages at stake to equal 1, so that if the plaintiff were to prevail at trial against all $N$ defendants, for example, each would pay $\frac{1}{N}$. Let $p$ represent the probability that the plaintiff prevails against any given defendant, where $0<p<1$. If the plaintiff and the defendants have different subjective estimates of $p$, then let $p_{p}$ represent the plaintiff's estimate and $p_{d}$ represent the defendants' common estimate.

The plaintiff makes a settlement offer to each of the defendants simultaneously, who must either accept the offer and pay the proposed amount in a settlement or reject the offer. If some defendants reject the offer, then the plaintiff will litigate against the nonsettling defendants. ${ }^{8}$ Litigation would impose costs on the parties: $c_{p}$ on the plaintiff, and $c_{d}$ on each defendant, where $c_{p} \geq 0$ and $c_{d} \geq 0$. The defendants respond simultaneously and noncooperatively to the plaintiff's settlement offer. All parties are risk neutral.

Suppose the $N$ defendants are divided into $n$ groups, where $n$ is an integer and $1 \leq$ $n \leq N$. The $n$ groups may be of unequal size. Within each group, the probabilities that the plaintiff will succeed at trial against the defendants are perfectly correlated. Among the $n$ groups, however, the probabilities of success against the groups of defendants at trial are independent. Thus, $n$ is a parameter that indicates the degree to which the outcomes at trial are independent among the defendants: if $n=1$, then the outcomes are perfectly correlated among all defendants, but if $n=N$, then the outcomes are independent among all defendants. In between these polar cases are cases with some mix of correlation and independence.

Let $s_{p}$ represent the plaintiff's expected payoff from litigating against all $N$ defendants. Under joint and several liability, the plaintiff will receive 1 unless it fails against each group

\footnotetext{
${ }^{8}$ Like Kornhauser and Revesz (1994), we assume that the plaintiff can commit itself to litigate against nonsettling defendants. This assumption seems especially reasonable in the Superfund context, in which the plaintiff (the EPA) is an extreme example of a repeat player that has much to gain by building a reputation for litigating against nonsettling defendants.
} 
of defendants. Against each group, the probability of failure is $1-p$. Therefore:

$$
s_{p}=1-\left(1-p_{p}\right)^{n}-c_{p}
$$

For the plaintiff to be willing to make a settlement offer of $\frac{s}{N}$ to each defendant,

$$
s_{p} \leq s
$$

is a necessary condition; otherwise, the plaintiff would prefer litigation against all defendants over such a settlement.

Consider the defendant's decision whether to accept such a settlement offer or to litigate instead. It would be a Nash equilibrium for each defendant to accept the offer if each defendant expects litigating against the plaintiff alone (after all other defendants have accepted the offer) to yield a lower payoff than paying $\frac{s}{N}$ to the plaintiff in a settlement. The defendant would calculate its expected payoff from rejecting an offer $\frac{s}{N}$ when all other defendants have accepted this offer, taking into account the setoff that a court would apply under the unconditional pro tanto rule as a result of the $N-1$ other defendants settling for $\frac{s}{N}$ per defendant. A court would hold a losing defendant liable for $\max \left[0,1-(N-1) \frac{s}{N}\right]$. Assume that a court would not allow a suit for zero damages to go forward, so that defendants would have no incentive to accept a settlement offer if $s \geq \frac{N}{N-1}$. Thus:

$$
s<\frac{N}{N-1}
$$

is a necessary condition for the offer to be acceptable. Assuming that the plaintiff makes an offer consistent with (3), a defendant rejecting such an offer and choosing instead to litigate alone would face a probability of $p_{d}$ of being held liable for $1-(N-1) \frac{s}{N}$ in damages. For each defendant to settle for the amount $\frac{s}{N}$,

$$
\frac{s}{N} \leq p_{d}\left[1-(N-1) \frac{s}{N}\right]+c_{d}
$$


is a necessary condition. Solving (4) for $s$, we can restate this necessary condition as:

$$
s \leq s_{d},
$$

where:

$$
s_{d}=\frac{p_{d}+c_{d}}{p_{d}+\frac{1-p_{d}}{N}}
$$

Assume that if it is a Nash equilibrium for all defendants to accept such an offer, then all defendants will accept this offer. ${ }^{9}$

Given that $s_{p}<\frac{N}{N-1}$, there will always be an $s$ that satisfies necessary conditions (2) and (3). Putting necessary conditions (2), (3), and (5) together, therefore, we can state that such a settlement is possible only if there exists an $s$ that satisfies:

$$
s_{p} \leq s \leq s_{d}
$$

We can express our necessary condition as follows:

$$
1-\left(1-p_{p}\right)^{n}-c_{p} \leq \frac{p_{d}+c_{d}}{p_{d}+\frac{\left(1-p_{d}\right)}{N}} .
$$

Let $S$ denote the size of the "settlement range," such that:

$$
S=s_{d}-s_{p}=\frac{p_{d}+c_{d}}{p_{d}+\frac{\left(1-p_{d}\right)}{N}}+\left(1-p_{p}\right)^{n}+c_{p}-1
$$

We can now show:

Proposition 1 If $S>0$, then the plaintiff will not litigate against all defendants. If $S<0$, then the plaintiff will not settle with all defendants.

Proof: See Appendix.

\footnotetext{
${ }^{9}$ Like Kahan (1996), we focus on this Nash equilibrium in order to emphasize the aspects of the model that are most relevant for our purposes. Kornhauser and Revesz (1994) examine other Nash equilibria and show how the plaintiff would avoid equilibria with litigation by making appropriate asymmetric offers.
} 
Remark: A positive settlement range is sufficient to ensure that the plaintiff would rather settle with all defendants than litigate against all defendants. A negative settlement range is sufficient to ensure that the plaintiff would rather litigate against all defendants than settle on any terms that are acceptable to all defendants. These possible terms include unequal settlement shares for the defendants. That is, if the parties would not all agree to any settlement based on equal shares for the defendants, then they would not all agree on any other settlement either. In this sense, $S$ represents a general indicator of the likelihood of settlement among the parties.

We can also derive some general comparative statics results. In order to focus on cases in which the likelihood of settlement might change in response to changes in any of the parameters, assume that litigation costs are not so large as to make settlement a certainty. Specifically, assume:

$$
c_{p}<1-\left(1-p_{p}\right)^{n}
$$

so that the plaintiff has a positive expected payoff from litigation against all the defendants: $s_{p}>0$. Otherwise, the plaintiff would always prefer a settlement for 0 over litigation against all defendants. Also assume:

$$
c_{d}<\frac{1-p_{d}}{N} .
$$

Otherwise, $s_{d}>1$, and the defendants would always be willing to pay the full amount at stake in a settlement rather than litigate. We can now show the following:

Proposition 2 The settlement range $S$ is strictly increasing in $c_{d}, c_{p}, p_{d}$ and $N$, and strictly decreasing in $p_{p}$ and $n$.

Proof: See Appendix.

Remark: Higher litigation $\operatorname{costs}$ (higher $c_{d}$ and $c_{p}$ ) and more pessimistic expectations regarding trial outcomes (higher $p_{d}$ and lower $p_{p}$ ) both promote settlement by making litigation less attractive compared to a settlement. These comparative static results are familiar from the case of nonjoint liability: that is, one would expect to find these effects even if the $N$ 
defendants were each separately liable for its own $\frac{1}{N}$ share of the total amount at stake. The effect of $n$ on the settlement range, however, is unique to a regime of joint and several liability. Under a regime of nonjoint liability, the degree of correlation between trial outcomes among the defendants would not affect the settlement range.

As $n$ ranges from 1 to $N$, we move from the case of perfectly correlated trial outcomes among all defendants to the case of independent outcomes for all defendants. This decrease in correlation among trial outcomes makes litigation against all defendants more attractive for the plaintiff, because it increases the plaintiff's expected payoff from trial. This increase in $s_{p}$ makes settlement less likely. It becomes more likely that either the defendants or the plaintiff must be more pessimistic, or litigation costs must be higher, in order to make a settlement with all defendants possible. The effect of $n>1$ represents the potential settlement-inhibiting effect of joint and several liability.

The effect of $N$ on settlement includes an effect that is unique to joint and several liability. Under nonjoint liability, one would expect a large $N$ to promote settlement in the following sense: if each defendant is liable for only $\frac{1}{N}$ of the total damages at stake, then as $N$ grows large the amount at stake for each defendant grows small compared to its litigation $\operatorname{costs} c_{d}$. As $c_{d}$ looms larger compared to the stakes for each defendant, this effect tends to promote settlement even if liability is nonjoint or instead of joint and several. If, however, we hold constant the ratio between litigation costs and the amount at stake per defendant, for example, if $c_{d}=0$, then $N$ would have no effect on the settlement range under nonjoint liability.

Under joint and several liability, however, $N$ has a unique effect, which tends to promote settlement even if we hold constant the ratio between litigation costs and the amount at stake per defendant (for example, if $c_{d}=0$ ). As $N$ increases, the prospect of litigating alone becomes less attractive for a defendant contemplating a settlement offer. A larger $N$ implies that each defendant would pay a smaller fraction $\frac{1}{N}$ of a settlement, but if it instead litigates, then it faces the prospect of losing at a trial in which it could be held liable for the whole amount of damages (minus a setoff for the settlement with the other 
defendants). Therefore, as $N$ grows large, litigation becomes less attractive to each defendant compared to a settlement for any given total amount, and the plaintiff can therefore extract a larger total amount in a settlement with all $N$ defendants. This increase in $s_{d}$ makes settlement more likely. It becomes more likely that either the defendants or the plaintiff must be more optimistic to make a settlement with all defendants impossible. This effect of $N>1$ represents the potential settlement-promoting effect of joint and several liability. Thus, under joint and several liability, if both $N>1$ and $n>1$, then these two parameters exert opposing effects on the settlement range.

To translate effects on the settlement range into an effect on the probability of settlement, it will be useful to introduce some more precise proxies for the likelihood of settlement. Define $p_{d}^{*}$ as the $p_{d}$ that solves the equation $S=0$, so that the plaintiff would be just willing to settle with all defendants. If $p_{d}<p_{d}^{*}$, then settlement among all parties will not occur. Thus, for a given distribution of $p_{d}$, a higher value for $p_{d}^{*}$ implies that settlement is less likely. We can also define $p_{p}^{*}$ as the $p_{p}$ that solves the equation $S=0$. If $p_{p}>p_{p}^{*}$, then settlement among all parties will not occur. Thus, for a given distribution of $p_{p}$, a lower value for $p_{p}^{*}$ implies that settlement is less likely. Similarly, we can define $c_{d}^{*}$ as the $c_{d}$ that solves the equation $S=0$ and define $c_{p}^{*}$ as the $c_{p}$ that solves the equation $S=0$. Thus, $c_{d}^{*}$ and $c_{p}^{*}$ represent measures of the litigation costs necessary to make settlement among all parties possible. For a given distribution of $c_{d}$ and $c_{p}$, higher values for $c_{d}^{*}$ and $c_{p}^{*}$ imply that settlement is less likely. We can solve for each of these indicators, $p_{d}^{*}, p_{p}^{*}, c_{d}^{*}$, and $c_{p}^{*}$, as a function of the other parameters and take each to be an alternative measure of how these other parameters affect the likelihood of settlement. If we set equation (9) equal to 0, we can show the following comparative statics results:

Proposition 3 (a) $p_{d}^{*}$ is strictly increasing in $n$ and strictly decreasing in $N$, $c_{p}$, and $c_{d}$,

(b) $p_{p}^{*}$ is strictly decreasing in $n$ and strictly increasing in $N, c_{p}$, and $c_{d}$,

(c) both $c_{d}^{*}$ and $c_{p}^{*}$ are strictly increasing in $p_{p}$ and $n$ and strictly decreasing in $p_{d}$ and $N$.

Proof: See Appendix. 
Remark: The comparative statics results for $p_{d}^{*}, p_{p}^{*}, c_{d}^{*}$, and $c_{p}^{*}$ are precisely what one would expect from the comparative statics results for $S$. The same factors that cause the settlement range to shrink also imply that more pessimistic beliefs regarding trial outcomes or higher litigation costs are necessary to make settlement among all parties possible. The same factors that cause the settlement range to expand also imply that more optimistic beliefs regarding trial outcomes or lower litigation costs are necessary to preclude settlement among all parties.

Let us now consider some special cases of particular interest. To isolate the effect of joint and several liability (with the unconditional pro tanto rule), it will be useful to consider the case in which $c_{p}=c_{d}=0, p_{d}=p_{p}=p$, and $N=n=1$. In this baseline case, because $N=1$, joint and several liability can have no effect. Notice that if $N=1$, condition (8) simplifies to identify the familiar settlement range in cases under nonjoint liability for an amount of damages equal to $1 .^{10}$

Proposition 4 If $c_{p}=c_{d}=0, p_{d}=p_{p}=p$, and $N=n=1$, then $s_{p}=s_{d}, S=0$, and the parties will be willing to settle for an amount $s=s_{p}=s_{d}$.

Proof: This result should be obvious from an inspection of equation (9).

Now consider cases in which $N>1$. Comparing these cases with our baseline case reveals the effect of joint and several liability (with the unconditional pro tanto rule). Thus, if $S>0$, then the liability regime increases the settlement range and in this sense promotes settlement; if $S<0$, then the liability regime reduces the settlement range and in this sense inhibits settlement. We will analyze two polar cases in turn: $n=1$ and $n=N$. We can show the following:

Proposition 5 If $c_{p}=c_{d}=0$, and $n=1$, then:

(a) If $p_{d}=p_{p}=p$ and $N>1$, then $S>0$ and the plaintiff will settle with all defendants.

\footnotetext{
${ }^{10}$ This case is the equivalent of nonjoint liability for $N>1$ defendants, in which each defendant is liable for $\frac{1}{N}$, as long as we assume that litigation costs equal zero, so that setting the amount at stake to equal 1 has no real effect.
} 
(b) If $p_{d}=p_{p}=p$, and we consider $S$ as a function of $N$, we find that $S(N)$ rises monotonically from $S(1)=0$ toward $1-p$ as $N$ approaches infinity.

(c) If we consider $p_{d}^{*}$ as a function of $N$, we find that $p_{d}^{*}(N)$ falls monotonically from $p_{d}^{*}(1)=p_{p}$ toward 0 as $N$ approaches infinity.

(d) If we consider $p_{p}^{*}$ as a function of $N$, we find that $p_{p}^{*}(N)$ rises monotonically from $p_{p}^{*}(1)=p_{d}$ toward 1 as $N$ approaches infinity.

Proof: See Appendix.

Remark: If outcomes at trial are perfectly correlated among all $N$ defendants, then joint and several liability (with the pro tanto rule) promotes settlement by expanding the settlement range. As $N$ goes from 1 to $N>1$, the settlement range goes from zero to positive. If $N>1$, then for the plaintiff to find settlement with all defendants to be impossible, the parties must be relatively optimistic about their prospects at trial $\left(p_{d}<p_{p}\right)$. As $N$ grows larger, so does $S$.

The more positive $S$ becomes, the more optimistic the parties must be to make a settlement among all parties impossible. For example, $p_{d}^{*}$ represents the belief among defendants that is necessary to prevent settlement among all the parties in spite of joint and several liability and the unconditional pro tanto rule. We can take $p_{d}^{*}$ to be another measure of the effect of joint and several liability (with the unconditional pro tanto rule) upon settlement. Similarly, $p_{p}^{*}$ represents the plaintiff's belief that is necessary to prevent settlement among all the parties in spite of joint and several liability and the unconditional pro tanto rule. From either perspective, the degree of optimism required to prevent settlement (and thus the probability of settlement) increases in $N$.

Proposition 6 If $c_{p}=c_{d}=0$, but we constrain $n$ such that $n=N$, then:

(a) If $p_{d}=p_{p}=p$ and $N>1$, then $S<0$ and the plaintiff will not settle with all defendants.

(b) If $p_{d}=p_{p}=p$, and we consider $S$ as a function of $N$, we find that $S(N)$ is not monotonic: $S(N)$ falls from $S(1)=0$ and remains negative as long as $N>1$, but reaches a unique local minimum and then rises back toward 0 as $N$ approaches infinity. 
(c) If we consider $p_{d}^{*}$ as a function of $N$, we find that $p_{d}^{*}(N)$ rises monotonically from $p_{d}^{*}(1)=p_{p}$ toward 1 as $N$ approaches infinity

(d) If we consider $p_{p}^{*}$ as a function of $N$, we find that $p_{p}^{*}(N)$ falls monotonically from $p_{p}^{*}(1)=p_{d}$ toward 0 as $N$ approaches infinity.

Proof: See Appendix.

Remark: If outcomes at trial are independent among all $N$ defendants, then joint and several liability (with the pro tanto rule) inhibits settlement by reducing the settlement range. As $N$ goes from 1 to $N>1$, the settlement range goes from zero to negative. If $N>1$, then to achieve a settlement among all parties, litigation costs must be positive $\left(c_{p}>0\right.$ or $\left.c_{d}>0\right)$ or the parties must be relatively pessimistic about their prospects at trial $\left(p_{p}<p_{d}\right)$.

The settlement range remains negative as long as $N>1$, but it rises toward zero as $N$ grows large. As long as $n>1$, joint and several liability has a settlement-inhibiting effect as well as a settlement-promoting effect. The effect from $n$, which we have assumed equals $N$, upon the plaintiff's minimum settlement demand $s_{p}$ dominates the effect from $N$ upon the defendant's maximum settlement $s_{d}{ }^{11}$

Although $S$ suggests that $N$ has a nonmonotonic effect on the likelihood of settlement, $p_{d}^{*}$ and $p_{p}^{*}$ suggest that $N$ has a monotonic effect. As $N$ grows larger, the parties must be more pessimistic to make a settlement among all parties possible. For example, $p_{d}^{*}$ represents the belief among defendants that is necessary to make settlement among all the parties possible in spite of joint and several liability and the unconditional pro tanto rule. Similarly, $p_{p}^{*}$ represents the plaintiff's belief that is necessary to make settlement among all the parties possible in spite of joint and several liability and the unconditional pro tanto rule. From either perspective, the degree of pessimism required to make settlement possible increases in $N$. Thus, one would expect the probability of settlement to fall as $N$ grows large.

\footnotetext{
${ }^{11}$ As $N$ grows larger, both $s_{p}$ and $s_{d}$ approach 1 , and the gap between them must fall. The rate of increase in each variable slows and approaches zero, but the rate of increase in $s_{p}$ falls below the rate of increase in $s_{d}$, which causes $S$ to become less negative.
} 
The contrast between the shape of the $p_{d}^{*}(N)$ and $p_{p}^{*}(N)$ functions on the one hand and the $S(N)$ function on the other suggest that a focus on the settlement range alone as an indicator of the likelihood of settlement can be misleading. These results indicate that our hypotheses regarding the effect on settlement rates may depend upon our underlying model of what leads parties to settle in spite of the effects of joint and several liability and the unconditional pro tanto rule. Our reliance on $p_{d}^{*}$ and $p_{p}^{*}$ assumes that pessimism regarding outcomes at trial accounts for settlements under these circumstances. We might, however, look at litigation costs as another possible explanation for settlements in these cases.

The more negative $S$ becomes, the larger litigation costs must be to make a settlement among all parties possible. Recall that $c_{d}^{*}$ and $c_{p}^{*}$ represent alternative measures of the litigation costs necessary to induce settlement in spite of joint and several liability and the unconditional pro tanto rule. We can solve for $c_{d}^{*}$ and $c_{p}^{*}$ as functions of $N$ and take $c_{d}^{*}(N)$ and $c_{p}^{*}(N)$ to be another way to measure of the inhibiting effect of joint and several liability (with the unconditional pro tanto rule) upon settlement. We can show that neither $c_{d}^{*}(N)$ nor $c_{p}^{*}(N)$ is monotonic:

Proposition 7 If $p_{d}=p_{p}=p$ and we constrain $n$ such that $n=N$, then:

(a) If $c_{p}=0$ and we consider $c_{d}^{*}$ as a function of $N$, we find that $c_{d}^{*}(N)$ rises from $c_{d}^{*}(1)=0$ and remains positive as long as $N>1$, then reaches a unique local maximum and then falls back toward 0 as $N$ approaches infinity

(b) If $c_{d}=0$ and we consider $c_{p}^{*}$ as a function of $N$, we find that $c_{p}^{*}(N)$ rises from $c_{p}^{*}(1)=0$ and remains positive as long as $N>1$, then reaches a unique local maximum and then falls back toward 0 as $N$ approaches infinity.

Proof: See Appendix.

Remark: For $N=1$, joint and several liability will have no effect on settlement incentives and thus $c_{d}^{*}=c_{p}^{*}=0$. For $N>1$, that liability regime tends to inhibit settlement and thus $c_{d}^{*}>0$ and $c_{p}^{*}>0$. As $N$ grows large, however, $c_{d}^{*}$ and $c_{p}^{*}$ both decrease in $N$ and approach zero asymptotically. 
Suppose litigation costs (as a fraction of the total amount at stake in a case) differ from case to case and are distributed over an interval from zero to some value greater than the maxima of $c_{d}^{*}$ and $c_{p}^{*}$, so that some cases settle and others do not. If cases fail to settle because of the effects of joint and several liability and the unconditional pro tanto rule and we assume that the distribution of litigation costs is constant as $N$ grows large, then we would expect the settlement rate to be inversely related to $c_{d}^{*}$ and $c_{p}^{*}$.

On the other hand, if beliefs about prospects for success at trial differ from case to case, and this variation accounts for which cases settle, then we would expect the settlement rate to be related to $p_{d}^{*}$ and $p_{p}^{*}$, which would imply that the settlement rate would be a monotonic function of $N$. Thus, whether $N$ has a monotonic effect on the settlement rate would depend on what type of heterogeneity predominates in the sample of cases that we observe.

\section{Data}

To explore these relationships empirically, we study federal civil suits for cleanup of sites under CERCLA, also know as Superfund. Defendants in these cases may include past and present site owners as well as waste generators and transporters who contributed waste to the site. The EPA refers to these parties as Potentially Responsible Parties (PRPs).

\subsection{EPA Civil Docket Data}

Our basic data source on these disputes is the EPA's Civil Docket, which contains records of civil referrals by the EPA to the Department of Justice through March 1997. For each case referred, the data provide a list of defendants, filing and conclusion dates, and the outcome of the case. Some cases have data on the value of settlements or costs recovered in court, but these data are missing too often for use in our analyses. The docket reports only one outcome for each case; if some defendants settle in a dispute and others litigate, then the dispute splits into two "cases." Because of this endogeneity in the definition of a case, Table 1 and the later empirical analyses focus on defendants rather than cases as the level 
of observation.

We selected defendants in cases pertaining to nonfederal facility sites on the National Priorities List (NPL) sites. Superfund liability applies to other contaminated sites in addition to those on the NPL; however, only NPL sites have the full range of explanatory data and thus are included in our analyses. We excluded federal facility NPL sites because procedures differ at these sites from most NPL sites. The docket contains 8732 defendants in 1024 cases pertaining to nonfederal facility NPL sites.

In addition, the analysis is limited to NPL sites without de minimis PRPs. In 1986, Congress required the EPA to develop special settlement procedures for de minimis PRPs, often generators or transporters who contributed very small waste volumes (Kornhauser and Revesz, 1995b). These PRPs may satisfy their liability by paying a small share of cleanup costs. Because a special procedure applies to these settlements, we wish to exclude them from the analysis. A handful of cases in the docket data refer to CERCLA section 122(g), ${ }^{12}$ which authorizes de minimis settlements. However, not all the data contain detailed statutory references, so many cases that involve de minimis PRPs do not refer to CERCLA section 122(g). Thus, to be sure we exclude all de minimis PRPs, the analysis includes only cases at sites with no de minimis PRPs. ${ }^{13}$ A total of 1138 defendants in 488 cases remain following these exclusions.

Table 1 shows the results of civil disputes pertaining to NPL sites without de minimis PRPs. Of the 847 defendants for which the dispute had reached a resolution, 766 (or 90.4\%) had settled with the agency and only 22 (under 2.6\%) had litigated to judgement. This trial rate is somewhat lower than the values that Eisenberg and Farber (1997) report for all federal civil litigation. The remaining 59 defendants had other outcomes, including cases dismissed by the court, cases dropped by the government, and cases recorded as result "unknown." The

\footnotetext{
${ }^{12} 24$ USC $\S 9622(\mathrm{~g})$

${ }^{13}$ The EPA's 1993 Survey of Remedial Program Managers contains information on the numbers of de minimis PRPs at each site. We used these data to exclude observations. This exclusion reduced the sample to 495 cases and 1759 defendants. In addition, the sample excludes sites with more than 100 PRPs because it seems likely that such sites include some de minimis PRPs. This further exclusion reduced the sample by 7 cases and 621 defendants.
} 
Table 1: Descriptive statistics by defendant

\begin{tabular}{|c|c|c|c|c|}
\hline & \multicolumn{4}{|c|}{ Outcome: } \\
\hline & \multirow[b]{2}{*}{ Settled } & \multirow[b]{2}{*}{ Litigated } & \multirow{2}{*}{$\begin{array}{c}\text { In } \\
\text { progress }\end{array}$} & \multirow[b]{2}{*}{ Other } \\
\hline & & & & \\
\hline \multirow[t]{2}{*}{ Number of defendants } & 766 & 22 & 286 & 59 \\
\hline & \multicolumn{4}{|c|}{ Means (and standard deviations) } \\
\hline Case duration (years) & 2.17 & 2.76 & 5.79 & 1.68 \\
\hline & $(2.61)$ & $(2.66)$ & $(4.23)$ & $(1.59)$ \\
\hline \multicolumn{5}{|l|}{ Site characteristics: } \\
\hline Sole PRP & 0.06 & 0.14 & 0.02 & 0.05 \\
\hline Number of PRPs & $\begin{array}{c}17.42 \\
(14.77)\end{array}$ & $\begin{array}{c}7.77 \\
(4.62)\end{array}$ & $\begin{array}{c}18.91 \\
(15.43)\end{array}$ & $\begin{array}{c}14.41 \\
(10.81)\end{array}$ \\
\hline Off-site contributors & 0.60 & 0.18 & 0.76 & 0.33 \\
\hline Contamination after 1980 & 0.47 & 0.91 & 0.48 & 0.53 \\
\hline Cleanup cost (million $1997 \$$ ) & $\begin{array}{c}23.21 \\
(16.12)\end{array}$ & $\begin{array}{c}26.84 \\
(17.13)\end{array}$ & $\begin{array}{c}28.32 \\
(18.88)\end{array}$ & $\begin{array}{c}27.16 \\
(16.75)\end{array}$ \\
\hline Cost per PRP (million $1997 \$$ ) & $\begin{array}{c}4.21 \\
(8.10)\end{array}$ & $\begin{array}{c}6.08 \\
(9.68)\end{array}$ & $\begin{array}{c}2.80 \\
(4.03)\end{array}$ & $\begin{array}{c}4.67 \\
(6.37)\end{array}$ \\
\hline \multicolumn{5}{|l|}{ Defendant characteristics: } \\
\hline Firm & 0.78 & 0.82 & 0.77 & 0.71 \\
\hline Number of other sites & $\begin{array}{c}9.20 \\
(18.17)\end{array}$ & $\begin{array}{c}0.95 \\
(2.01)\end{array}$ & $\begin{array}{c}8.04 \\
(16.69)\end{array}$ & $\begin{array}{c}7.19 \\
(18.65)\end{array}$ \\
\hline
\end{tabular}

Notes: For continuous variables, standard deviations in parentheses.

Other outcomes: 21 cases combined with another, 19 dismissed by court, 7 voluntarily dismissed, 12 unknown. 
empirical analyses in the next section drop these 59 defendants. Finally, for 286 defendants, the case was still in progress as of March 1997. As the table reports, these cases had been in progress for an average of 5.8 years, compared to 2.2 years for settled cases and 2.8 years for litigated cases.

\subsection{Explanatory variables}

Explanatory variables derive from a few data sets that we merged with the docket data. As a measure of $N$, we collected data on the number of PRPs at the site. The Site Enforcement Tracking System (SETS) provides names and address of PRPs who have been sent notice letters. Unfortunately, the SETS is incomplete (although the omissions do not seem to be systematic), so we supplemented these PRP lists with the list of defendants at any case pertaining to the site. ${ }^{14}$ To represent $N$, we use the total count of PRPs, rather than the count of defendants, because the total PRP count represents all potentially liable parties. If the EPA prevails against a first group of PRPs, other PRPs may never appear as defendants, but we would still wish them to be included in $N$.

As reported in Table 1, defendants who settle are at sites that average about 17 PRPs, compared to only 8 PRPs for defendants who litigate. A significant number of both settling and litigating defendants are sole PRPs, but this status is more common for litigating defendants. Thus, the table suggests that defendants at multiple PRP sites might settle preferentially. However, the two groups of defendants differ in other ways too, so a multiple regression is necessary to confirm this difference.

The degree of correlation in the outcome at trial, measured in the model by the number of types of defendants, $n$, is more difficult to observe. We use indicators that point to differences in possible defense strategies. One possible measure is whether PRPs include off-site waste generators and transporters in addition to past and present owners of the site. Off-site PRPs may have an easier time offering defenses that deny involvement at the sites than on-site

\footnotetext{
${ }^{14}$ We have tried to define defendants as parent companies, counting only one defendant when multiple subsidiaries are named as defendants at a site.
} 
PRPs. Alternatively, a small number of site owners have successfully used an "innocent landowner" defense that would not be available to waste generators or transporters. ${ }^{15}$ Thus, the existence of the two kinds of PRPs may reduce correlation in outcomes at trial.

Data on whether sites have off-site contributors among their PRPs derive from a 1993 survey of Remedial Program Managers (RPMs), the officials in charge of overseeing site cleanup at each NPL site (U.S. EPA, 1995). As Table 1 reports, $60 \%$ of settling defendants are at sites with off-site contributors, compared to only $18 \%$ of litigating defendants. Although this comparison would suggest that greater differentiation among defendants encourages settlement, counter to our theoretical predictions, the presence of off-site PRPs is strongly related to the number of PRPs. Thus, the apparent association may only be the result of this correlation.

A second possible measure of diversity in PRP defenses is whether some contamination occurred after 1980. Virtually all sites had some contamination prior to 1980, the year that Superfund passed, but only some sites had additional contamination after 1980. If the same PRPs contributed both the early and late contamination, whether the site has contamination in both periods will have no effect on correlations. However, if contamination at different times is the contribution of different defendants, the difference in timing across defendants may cause them to offer different defenses. Because of the Resource Conservation and Recovery Act (RCRA) ${ }^{16}$ instituted requirements for "cradle to grave" tracking of hazardous waste in the late 1970s, the sources of contamination are probably better documented in the later period than the early period. PRPs associated with later contamination may therefore mount different defenses than other PRPs. Thus, for some sites, contamination over a longer period of time may indicate less correlation in outcomes at trial. In the table, litigating defendants are more likely to come from sites with recent contamination, which is consistent with this interpretation.

In addition to the variables $N$ and $n$, the model suggests that the amount at stake

\footnotetext{
${ }^{15} 24$ USC $\S 9601(35)(B)$.

${ }^{16} 42$ USC $\S \S 6901-6992 \mathrm{~A}$.
} 
may influence the likelihood of settlement. Litigation costs, $c_{d}$ and $c_{p}$, enter the equations normalized by the amount at stake. As a result, this amount should affect $c_{d}$ and $c_{p}$ and thus enter the estimated equations, unless absolute litigation costs vary exactly proportionately with the amount at stake. If litigation costs rise less than proportionately with the amount at stake (as seems likely), then an increase in this amount would have the opposite effect of an increase in litigation costs and thus tend to decrease settlement.

Previous empirical studies of settlement have found that stakes are an important predictor of settlement frequencies in single defendant contexts. Viscusi (1986) finds that high stakes discourage settlement of product liability claims, which is consistent with our expectations. However, Perloff and Rubinfeld (1988) find the reverse effect in antitrust cases. They attribute this effect to risk aversion, creating an insurance value from settling high stakes cases. Although risk aversion is absent from our formal model, this prior research suggests it may play a role in the empirical results.

In addition, to the total amount at stake, we also include the amount at stake per PRP. In the absence of this variable, $N$ might have settlement-promoting effects even under nonjoint liability. Assuming (as in our model) that PRPs have equal liability shares, each defendant's liability would decline with $N$ as the total stakes are split among all defendants. Because the stakes per defendant would fall relative to the litigation costs, settlement would rise with $N$. Thus, the equations include the stakes per defendant to isolate the effects of $N$ that flow uniquely from joint and several liability.

To measure the stakes in the disputes we study, we use the anticipated present value of cleanup costs at the site. Total site cleanup costs may overstate the true stakes in these disputes. The EPA sometimes divides cleanup projects by environmental media and area within the site and sues separately for these different projects. However, the EPA does not provide information on the amount it is seeking from specific groups of defendants. Indeed, the set of cleanup projects covered in a case may be a subject of negotiation. Thus, overall site costs are our best available proxy for the amount at stake.

The RPM survey provides data on expected total cleanup cost for most sites. However, 
the RPMs often failed to respond to these questions. For these sites, we used remedy costs in all Records of Decision (RODs) signed for the site through the end of fiscal year $1993 .{ }^{17}$ Table 1 reports that the present value of cleanup costs at the sites exceeds $\$ 20$ million (in 1997 dollars). Although litigating defendants appear to be associated with more costly sites than settling defendants, the difference is not statistically significant.

Finally, we would like measures of litigation costs, $c_{d}$ and $c_{p}$. Because the plaintiff is the same in all cases, measures of variation in the plaintiff's costs, $c_{p}$, are not obvious. However, heterogeneity across defendants may correlate with $c_{d}$. We employ two defendant characteristics that we can derive from the list of names provided in the docket. First, we coded defendants as firms and other types of defendants. Non-firm defendants include individuals and their estates, local governments, federal agencies, and non-profit organizations, particularly universities. Firms may have systematically higher or lower litigation costs because they are the least likely to indulge tastes for or against legal disputes. ${ }^{18}$ As Table 1 reports, $78 \%$ of settling defendants are firms.

A second defendant characteristic that may affect defendants' litigation costs is the number of other sites at which this defendant is also a PRP. There are several possible effects of this variable. On the one hand, the variable may discourage settlement for two reasons. Defendants who are PRPs at multiple sites may develop more legal expertise, tending to decrease their litigation costs. In addition, these defendants may have the incentive to establish reputations as hard bargainers, reducing their aversion to litigation and thus also tending to discourage settlement. On the other hand, this variable may promote settlement. PRPs with various sites may face higher public relations costs from appearing to thwart site cleanup. Thus, the defendant's litigation costs, $c_{d}$, may be higher at these sites. Furthermore, defendants with experience in the process may better evaluate their chances of success at trial, making it less likely that their false optimism will deter settlement.

\footnotetext{
${ }^{17} \mathrm{~A}$ small number of sites had no cost data from either source. For these sites, we predicted costs based on a regression of cost on many site descriptive characteristics, including Hazard Ranking Score, site acreage, contaminants, contaminated media, type of facility, and density of the local population.

${ }^{18}$ Eisenberg and Farber (1997) argue that market discipline will force firms to indulge both positive and negative tastes less freely than other litigants.
} 
Many PRPs have multiple exposures to Superfund: settling defendants averaged nine other sites in addition to the one in question. Most PRPs have only one site, but those with multiple sites tend to have dozens of sites. Defendants who litigated averaged fewer than one other site, much lower than the average for the whole dataset. Thus, the settlementpromoting effects of exposure at multiple sites may dominate.

\section{Econometric estimates}

This section presents two sets of estimated equations designed to explore the empirical implications of the theoretical model. The first set of equations study whether cases are settled or litigated, analyzing those defendants that had reached one or the other of these results. The second set of equations analyzes the time until settlement.

\subsection{Settlement versus litigation}

Following Proposition 1, we would expect to observe settlement when the unobserved settlement range, $S$, is positive and to observe litigation otherwise. To implement the model empirically, therefore, we estimate a binary choice model, in which observing settlement depends upon the variables that determine the sign of $S$. Conventionally, we assume that the unobserved heterogeneity has a normal distribution. Thus, the estimated model has the form:

$$
\operatorname{Pr}(\text { Settle }=1)=\Phi\left(f\left(N, n, c_{d}, c_{p}\right)\right),
$$

where $N$ is the number of PRPs, $n$ reflects the variables on PRP diversity, $c_{d}$ represents the variables that may affect defendants' litigation costs, such as amount at stake and defendant characteristics, and $c_{p}$ may also appear through the effects of amount at stake.

As discussed above, the defendant is the level of observation. Several defendant-level characteristics are among the variables of interest. However, correlation in the unobserved heterogeneity across defendants at the same site seems likely. This correlation may tend to bias down the standard errors of explanatory variables that vary only at the site level. 
To address this problem, we report probit estimates with standard errors corrected for the correlated error structure. ${ }^{19}$

Table 2 presents the probit estimates. The first column of the table compares settlement frequencies for defendants at multiple PRP sites with those at single PRP sites. The estimated coefficient is positive, but is not statistically different from zero. The positive point estimate is consistent with the hypothesis that joint and several liability on balance encourages settlement, as might occur with a generally high degree of correlation between the outcomes at trial for the PRPs. Based on the point estimate of .857 , a multi-PRP site is 4 percentage points more likely to settle than a comparable single PRP site. At the very least, the equation presents no evidence to support to claim that Superfund's joint and several liability on balance discourages settlement.

The total cost of cleanup at the site and the average cost per PRP also do not enter with statistically significant coefficients. The coefficients on these cost variables have opposite signs, an effect that is difficult to interpret. However, their standard errors are so large that one should not attribute much importance to this pattern.

The variables representing defendants' characteristics have mixed results. Firms do not appear to settle significantly more often than other types of defendants. Their litigation costs may not be significantly different on average from those of other types of defendants. However, increasing the number of sites at which this defendant is a PRP increases settlement. This coefficient is statistically significant at the $10 \%$ level in all the columns. Thus, this variable may have the effect of increasing the defendant's aversion to litigation or improving its forecast of trial outcomes.

The second column in the Table 2 replaces the multi-PRP dummy with a continuous variable for the number of PRPs. The coefficient on this variable is positive and statistically significant at the $5 \%$ level in this equation. The elasticity of settlement with respect to the number of PRPs at the sample means is .01; although this value appears small, it should

\footnotetext{
${ }^{19}$ Using Monte Carlo analysis, Guilkey and Murphy (1993) find that this estimator performs well in samples similar in size to our database. It compares favorably with random effects estimators, which often failed to converge for our models.
} 
Table 2: Determinants of settlement: probit estimates

\begin{tabular}{|c|c|c|c|c|}
\hline & \multicolumn{4}{|c|}{$\begin{array}{c}\text { Dependent variable: } \\
1 \text { if settle }\end{array}$} \\
\hline & (1) & (2) & (3) & (4) \\
\hline \multicolumn{5}{|l|}{ Site characteristics: } \\
\hline Multiple PRPs (dummy) & $\begin{array}{l}.857 \\
(.632)\end{array}$ & - & - & - \\
\hline Number of PRPs & - & $\begin{array}{c}.053 \\
(.016)\end{array}$ & $\begin{array}{l}-.134 \\
(.139)\end{array}$ & $\begin{array}{l}.045 \\
(.024)\end{array}$ \\
\hline $\begin{array}{l}\text { Number of PRPs squared } \\
\text { (divided by 100) }\end{array}$ & - & - & $\begin{array}{l}.764 \\
(.571)\end{array}$ & - \\
\hline Off-site contributors & - & - & - & $\begin{array}{l}.165 \\
(.352)\end{array}$ \\
\hline Contamination after 1980 & - & - & - & $\begin{array}{l}-.771 \\
(.275)\end{array}$ \\
\hline Cleanup cost & $\begin{array}{l}-.008 \\
(.010)\end{array}$ & $\begin{array}{l}-.011 \\
(.010)\end{array}$ & $\begin{array}{l}-.006 \\
(.011)\end{array}$ & $\begin{array}{l}-.007 \\
(.010)\end{array}$ \\
\hline Cost per PRP & $\begin{array}{l}.010 \\
(.021)\end{array}$ & $\begin{array}{l}.020 \\
(.024)\end{array}$ & $\begin{array}{l}-.004 \\
(.025)\end{array}$ & $\begin{array}{l}.013 \\
(.022)\end{array}$ \\
\hline \multicolumn{5}{|l|}{ Defendant characteristics: } \\
\hline Firm & $\begin{array}{l}-.298 \\
(.225)\end{array}$ & $\begin{array}{l}-.340 \\
(.215)\end{array}$ & $\begin{array}{l}-.384 \\
(.218)\end{array}$ & $\begin{array}{l}-.267 \\
(.230)\end{array}$ \\
\hline Number of other sites & $\begin{array}{l}.083 \\
(.043)\end{array}$ & $\begin{array}{l}.066 \\
(.035)\end{array}$ & $\begin{array}{l}.061 \\
(.030)\end{array}$ & $\begin{array}{l}.059 \\
(.030)\end{array}$ \\
\hline Constant & $\begin{array}{l}1.286 \\
(.649)\end{array}$ & $\begin{array}{l}1.573 \\
(.259)\end{array}$ & $\begin{array}{l}2.386 \\
(.590)\end{array}$ & $\begin{array}{l}2.074 \\
(.293)\end{array}$ \\
\hline $\begin{array}{l}\chi^{2} \text { for PRPs and PRPs squared } \\
\text { (p value) }\end{array}$ & - & - & $\begin{array}{l}4.60 \\
(.10)\end{array}$ & - \\
\hline Log-likelihood & -91.5 & -85.7 & -82.7 & -80.7 \\
\hline Pseudo-R ${ }^{2}$ & .089 & 147 & .176 & 196 \\
\hline
\end{tabular}

Notes: 788 observations. Standard-errors in parentheses adjusted for clustering at the site level. 
be considered in the context of the high overall settlement rate in our data. The positive coefficient on this variable tends to confirm Proposition 2, which holds that $N$ should increase the settlement range all else held constant. In addition, the result suggests that the data do not conform to Proposition 6 (the case of independent outcomes), in which $n$ grows with $N$ so that increases in $N$ reduce settlement incentives. The results are consistent with Proposition 5 (the case of perfect correlation), in which $n=1$ and increases in $N$ increase settlement. Thus, as before, the results provide no evidence that joint and several liability reduces settlement and are at least consistent with the hypothesis that it encourages settlement.

To further explore whether Proposition 5 or Proposition 6 fits the data better, we add an $N^{2}$ term to the equation in column 3. This quadratic model does not fit the data very well. Neither the coefficient on the linear $N$ term nor that on the squared term is individually statistically significant, and their joint statistical significance is only borderline with a pvalue of exactly $10 \%$. The point estimates suggest that $N$ has settlement-deterring effect for small $N$, but a promoting effect for larger $N$. The quadratic function reaches a minimum at approximately $N=8$ and passes back through zero at about $N=17.5$, approximately the sample mean. An explanation of this pattern is that the conditions for Proposition 6 dominate for low $N$, that is $n$ grows with $N$. For higher $N$, however, $n$ does not grow with $N$, so Proposition 5 more accurately describes the data. However, the size of the standard errors make characterization of the functional form and thus of these relationships speculative.

The fourth column in Table 2 adds measures of the similarity of the defendants to examine the influence of correlation in trial outcome on settlement. Proposition 3 suggests that variables that correspond to lower $n$ should relax the conditions for settlement and thus raise settlement rates. Two such measures are included. The first measure, the presence of off-site PRPs, has a positive coefficient, which is counter to expectations, but the estimate is not statistically different from zero.

The second measure of correlation in column 4 is the timing of contamination. For reasons explained above, sites with contamination after 1980 may have lower correlation in outcomes. The estimated coefficient is statistically significant and negative, consistent with 
this hypothesis. The point estimate corresponds to a 0.8 percentage point lower settlement rate at sites with later contamination. Thus, the estimates provide some support for the model's prediction about the influence of correlation on settlement incentives.

A concern with this analysis is that the observations are selected based upon whether an outcome is observed by March 1997. ${ }^{20}$ The large number of defendants whose cases are still in progress suggest that the results might be different when all cases have finished than they appear at this interim state. However, it is possible that some cases indicated as in progress are in fact cases that the government has ceased to pursue but not formerly dropped. To illustrate, defendant completion rates are little higher for cases filed prior to 1985 (76\%) than for those filed later (75\%). Thus, many "in progress" cases may actually be cases that are not be expected ever to reach either settlement or litigation.

\subsection{Time to settlement}

A second set of equations explore the determinants of the speed with which settlement occurs. Although a less direct test of the model than the first set of equations, this second set of equations has the advantage of richer variation in its dependent variable than the binary outcomes above.

Our theoretical model assumes simultaneous one-time offers, abstracting from all questions of timing. Thus, we do not have a formal model of time to settlement. ${ }^{21}$ However, it seems plausible that parties will find acceptable settlements sooner when settlement incentives are stronger. Thus, factors that typically reduce the litigation costs necessary for settlement or increase the allowable degree of optimism should also encourage speedier settlements.

\footnotetext{
${ }^{20}$ We attempted to address this problem by estimating a bivariate probit selection model. The model has two equations: one equation determines whether a case has an outcome yet, and conditional on it having an outcome, a second equation indicates whether this outcome is settlement or litigation. To identify the second equation, we included variables indicating the time of filing of the case in the first equation only. This approach follows Eisenberg and Farber (1997). Unfortunately, we were unable to obtain convergence for this model. The difficulty may stem from the small number of litigated observations.

${ }^{21}$ For a theoretical model of time to settlement in a single defendant context, see Spier (1992). Previous empirical work on time to settlement includes Kessler (1996) and Eisenberg and Farber (1997).
} 
To study the determinants of time to settlement empirically, we study the time between when a case is filed and when settlement occurs. Because the filing date is potentially endogenous, we previously estimated equations in which the duration began with the proposal of the site to the National Priorities List. The qualitative results were very similar across definitions, suggesting that endogeneity in filing time should not be a major concern. As a result, we use the more natural definition of the beginning of a case.

The sample for these equation includes all defendants who have settled by March 1997. It also includes data for defendants whose cases were still in progress at that time. Although a few of these cases in progress may litigate rather than settle, their numbers are very small. Thus, incorrectly including them as cases not yet settled should not significantly affect the results.

We estimate a proportional hazard model of the time until settlement. The fundamental component of the model is the hazard rate, $h$, which is the probability of settlement at time $t$ for an observation conditional on not having settled before $t$. The model assumes that the covariates, $X$, affect the hazard proportionately and enter the equation exponentially, as is conventional. Thus the function form for the equation is assumed to be:

$$
h(X, \beta, t)=\exp (X \beta) h_{o}(t)
$$

where $h_{o}(t)$ is the baseline hazard rate and the estimated coefficients are $\beta$.

The Cox partial likelihood model uses the order in which observations settle to estimate $\beta .^{22}$ This approach avoids the need for arbitrary assumptions about the functional form of the baseline hazard, $h_{o}(t)$. The observations are ranked in order of settlement times, with $i$ representing their position in this ordering. The probability that it is observation $i$ that settles at time $t_{i}$ rather than another observation that has not yet settled is

$$
\frac{h\left(X_{i}, \beta, t_{i}\right)}{\sum_{j=i}^{T} h\left(X_{j,} \beta, t_{j}\right)} .
$$

\footnotetext{
${ }^{22}$ For background, see Kiefer (1988).
} 
Assuming the proportional hazard function above, the partial likelihood for the sample is

$$
L=\prod_{i=1}^{T_{u}} \frac{\exp \left(X_{i} \beta\right)}{\sum_{j=i}^{T} \exp \left(X_{j} \beta\right)}
$$

where $T_{u}$ is the number of uncensored observations and $T$ is the total number of observations. Censored observations, which had not settled by March 1997, contribute only to the denominator. Any observation that has not settled after $t_{i}$ (whether censored or uncensored) appears in the summation of the denominator for the $i^{\text {th }}$ observation (the group "at risk" for settlement).

Table 3 contains estimates of coefficients $\beta$ from maximization of the log-likelihood. A positive coefficient indicates a higher hazard rate for settlement at any give time and thus a shorter time until settlement. As a result, variables with positive coefficients can be interpreted as settlement promoting as in the previous equations. Again, we adjusted the standard errors for clustering at the site level.

The columns in Table 3 use the same covariates as the columns in Table 2. The first column compares sites with multiple PRPs with sole PRP sites. As before, the estimated coefficient is positive but not statistically significant. There is at least no evidence to support the view that the presence of multiple PRPs delays settlement.

The cost variables have the same signs as in Table 2: the total cost delays settlement, whereas the cost per PRP encourages settlement. Unlike the estimates in Table 2, however, the cost coefficients in Table 3 are statistically significant. The negative coefficient on cleanup cost is expected because higher costs have the same effect as lower litigation costs in the model. However, finding a positive coefficient on costs per PRP negative is puzzling when the effect of total costs is negative.

The defendant characteristics also have coefficients of the same sign in Table 3 as in Table 2. The coefficient on the dummy variable for defendants that are firms is positive and statistically significant at the $10 \%$ level in the first column. However, when additional explanatory variables are added in the next columns, this coefficient is no longer statistically 
Table 3: Determinants of time to settlement: Cox proportional hazard estimates

\begin{tabular}{|c|c|c|c|c|}
\hline & \multicolumn{4}{|c|}{$\begin{array}{c}\text { Hazard rate for } \\
\text { settlement }\end{array}$} \\
\hline & $(1)$ & $(2)$ & $(3)$ & (4) \\
\hline \multicolumn{5}{|l|}{ Site characteristics: } \\
\hline Multiple PRPs (dummy) & $\begin{array}{l}.175 \\
(.341)\end{array}$ & - & - & - \\
\hline Number of PRPs & - & $\begin{array}{l}.010 \\
(.007)\end{array}$ & $\begin{array}{l}.010 \\
(.023)\end{array}$ & $\begin{array}{c}.021 \\
(.007)\end{array}$ \\
\hline $\begin{array}{l}\text { Number of PRPs squared } \\
(\div 10000)\end{array}$ & - & - & $\begin{array}{c}.034 \\
(2.88)\end{array}$ & - \\
\hline Off-site contributors & - & - & - & $\begin{array}{c}-.563 \\
(.232)\end{array}$ \\
\hline Contamination after 1980 & - & - & - & $\begin{array}{c}.254 \\
(.233)\end{array}$ \\
\hline Cleanup cost & $\begin{array}{l}-.017 \\
(.009)\end{array}$ & $\begin{array}{l}-.020 \\
(.010)\end{array}$ & $\begin{array}{l}-.020 \\
(.010)\end{array}$ & $\begin{array}{l}-.023 \\
(.009)\end{array}$ \\
\hline Cost per PRP & $\begin{array}{l}.041 \\
(.016)\end{array}$ & $\begin{array}{l}.046 \\
(.011)\end{array}$ & $\begin{array}{l}.046 \\
(.011)\end{array}$ & $\begin{array}{c}.043 \\
(.011)\end{array}$ \\
\hline \multicolumn{5}{|l|}{ Defendant characteristics: } \\
\hline Firm & $\begin{array}{l}.296 \\
(.174)\end{array}$ & $\begin{array}{l}.275 \\
(.177)\end{array}$ & $\begin{array}{l}.275 \\
(.178)\end{array}$ & $\begin{array}{l}.211 \\
(.166)\end{array}$ \\
\hline $\begin{array}{l}\text { Number of other sites } \\
(\div 100)\end{array}$ & $\begin{array}{r}.179 \\
(.275) \\
\end{array}$ & $\begin{array}{l}.102 \\
(.250) \\
\end{array}$ & $\begin{array}{l}.102 \\
(.247) \\
\end{array}$ & $\begin{array}{r}.356 \\
(.256) \\
\end{array}$ \\
\hline $\begin{array}{l}\chi^{2} \text { for PRPs and PRPs squared } \\
(p \text { value })\end{array}$ & - & - & $\begin{array}{l}3.49 \\
(.17)\end{array}$ & - \\
\hline Log-likelihood & -4755 & -4750 & -4750 & -4725 \\
\hline
\end{tabular}

Notes: 1052 observations; 766 uncensored. Standard-errors in parentheses adjusted for clustering at the site level. A higher coefficient indicates a higher hazard rate and a shorter expected time until settlement. 
significant. The number of other sites at which the defendant is listed as a PRP also has a positive sign, as before, but is not statistically significant in any of the equations.

The second column of Table 3 includes a continuous variable for the number of PRPs, as a measure of $N$. The coefficient on this variable is positive in column 2 but not statistically significant. Again, this estimate is inconsistent with Proposition 6 , in which $N$ discourages settlement. When we introduce controls for $n$, the positive coefficient on $N$ becomes statistically significant. This result confirms Proposition 2, which posits that the settlement range increases in $N$ when we hold other attributes of the case constant.

Column 3 extends the results the model to include a squared term in $N$. The point estimates suggest a relationship with $N$ that increases over the entire range of observations; the function peaks at about $N=75$, but the largest site in our data has 72 PRPs. Thus, the point estimates are consistent with Proposition 5 rather than Proposition 6. However, the coefficients on the $N$ and $N^{2}$ variables are neither individually nor jointly statistically significant, so it is not possible to draw any conclusion about this relationship.

In the fourth column, the presence of off-site contributors at the site appears to decrease the hazard rate for settlement and thus increase expected time until settlement. This coefficient is statistically significant at the $5 \%$ level. This estimate supports the expectation from the theoretical model that lower $n$ tends to discourage settlement. However, the coefficient on contamination after 1980 is positive, which is inconsistent with the model, but is not statistically significant.

\section{Conclusion}

Our results provide support for the leading theoretical model of parties' responses to joint and several liability. We find that diversity in PRPs discourages and delays settlement. Because diversity is likely to be associated with lower correlation among defendants in outcome at trial, this negative relationship supports our theoretical predictions. For example, in an alternative model in which defendants cooperate with one another in reaching settlement, 
we would not expect to see such a relationship. Furthermore, if cooperation becomes more difficult to sustain with larger numbers of defendants, the cooperative model would predict a negative relationship between the number of PRPs and settlement, but we find evidence of a positive relationship instead.

In addition, our results suggest that joint and several liability under CERCLA is more likely on balance to promote settlement than inhibit it. Previous theoretical research has concluded that the effect of joint and several liability on settlement is ambiguous a priori. In our data, the effect of the number of PRPs upon settlement is more consistent with the results predicted for the case of perfect correlation in trial outcomes among defendants (in which the liability regime promotes settlement) than with those predicted for the case of independent outcomes (in which the liability regime inhibits settlement). Current proposals would restrict joint and several liability in favor of nonjoint liability rules. Our results suggest that these changes will not reduce litigation between the EPA and PRPs and may in fact increase it.

An increase in litigation and delay of settlements could raise the overall transactions cost associated with the program. The level of these costs is already a serious concern. Recent studies by RAND indicate that they may account for 23 to $31 \%$ of total private Superfund expenditures (Dixon, 1995). Legal costs currently account for about $10 \%$ of the public spending on Superfund (U.S. EPA, 1994). If joint and several liability does encourage settlement, it could lower the government's costs. Its effects on private costs are ambiguous, however, since we have not considered suits for contribution against nonsettling PRPs. Nonetheless, avoiding legal costs does not provide a good rationale for changing Superfund's liability regime, given the results presented here. ${ }^{23}$

\footnotetext{
${ }^{23}$ Of course, there may be other reasons to maintain or change the liability regime. For example, joint and several liability may affect incentives for precaution against environmental contamination (see Kahan, 1996; Kornhauser and Revesz, 1995a; Spier, 1994; Tietenberg, 1989).
} 


\section{A Appendix}

Proof of Proposition 1: Consider an offer from the plaintiff to settle with each defendant for $\min \left[\frac{s_{d}}{N}, \frac{1}{N-1}\right]$ minus some infinitesimal amount. If $S>0$, then the plaintiff would prefer settlement with all defendants on such terms over litigation against all defendants. Each defendant would prefer to settle on these terms rather than litigate alone. Therefore, settlement among all parties is a Nash equilibrium among the defendants.

Consider an offer from the plaintiff to settle with each defendant for the amount just barely acceptable for the plaintiff: $\frac{s_{p}}{N}$. If $S<0$, then the defendants will not accept this offer. The plaintiff might also consider making an offer to settle with some defendants on terms better than those offered to other defendants. For such a settlement to be worthwhile for the plaintiff, offers below $\frac{s_{p}}{N}$ must be offset by other offers sufficiently above $\frac{s_{p}}{N}$ such that the plaintiff gets at least $s_{p}$ in total.

The defendant paying the most under such a settlement, however, would never accept such an offer, because it would do better by litigating alone against the plaintiff. That defendant would have even stronger incentives to litigate alone than it would under a symmetric offer to settle for $s_{p}$. Although it would have a greater expected liability if it litigates alone, because the setoff resulting from the settlement with the other $N-1$ defendants would be smaller than under the symmetric offer, the increase in that defendant's expected liability at trial would not be as great as the increase in the plaintiff's demand from that defendant in a settlement. The increase in the plaintiff's demand from that defendant must be at least as large as the decrease in the plaintiff's demands from the other $N-1$ defendants. Furthermore, the decreased settlement from the other $N-1$ defendants will impose a cost on the Nth defendant in terms of a reduced setoff only if that defendant loses at trial, which would occur only with probability $p_{d}$. Therefore, that defendant would strictly prefer to litigate alone rather than accept the plaintiff's settlement offer.

Proof of Proposition 2: We can derive all of our comparative statics results by totally differentiating equation (9) and taking the relevant partial derivatives of $S$, but most of these

results should be obvious from an inspection of equation (9). The only partial derivative 
that appears to be ambiguous is $S^{\prime}\left(p_{d}\right)$, which is strictly positive if and only if:

$$
c_{d}<\frac{1}{N-1}
$$

Assumption (11), however, ensures that inequality (12) must hold.

Proof of Proposition 3: We can derive all these comparative statics results by setting equation (9) equal to 0 , totally differentiating, then solving for the relevant partial derivatives of $p_{d}^{*}, p_{p}^{*}, c_{d}^{*}$, and $c_{p}^{*}$. Most of these results should be obvious, however, once we set equation (9) equal to 0 , solve for $p_{p}^{*}, c_{d}^{*}$, and $c_{p}^{*}$ in turn, and inspect the resulting expressions. The only partial derivatives that appear to be ambiguous pertain to $p_{d}$, but these all become unambiguous if inequality (12) holds, and assumption (11) ensures that inequality (12) must hold.

\section{Proof of Proposition 5:}

(a) It should be obvious from an inspection of equation (9) that if $c_{d}=c_{p}=0, p_{d}=p_{p}=p$, $n=1$, and $N>1$, then $S>0$. We can also show that the plaintiff will prefer to settle with all defendants rather than litigate against any. Suppose the plaintiff settles with $k$ defendants for an amount $s^{*}$ per defendant and litigates against the other $N-k$, where $1 \leq k \leq N$. The plaintiff's payoff will then be:

$$
k s^{*}+p\left[1-k s^{*}\right]
$$

If $k>0$, so that the plaintiff settles with at least one defendant, suppose also that the

plaintiff chooses the $s^{*}$ that is large enough that the each settling defendant is just barely willing to accept the settlement offer rather than join the $N-k$ defendants in litigating against the plaintiff. That is:

$$
s^{*}=p \frac{1-(k-1) s^{*}}{N+1-k} .
$$

The plaintiff cannot settle with $k$ defendants and enjoy a better payoff by offering unequal terms to the $k$ defendants, because the defendant paying the highest amount would refuse 
the offer and litigate instead, by reasoning similar to that used in the proof of Proposition 1.

If we solve equation (14) for $s^{*}$ and substitute in (13), we find that the plaintiff's payoff from settling with $k$ defendants is:

$$
p+\frac{(1-p) k p}{p N+(1-p)(N+1-k)}
$$

which is strictly increasing in $k$. Therefore, $k=N$ maximizes the plaintiff's payoff. The plaintiff will choose to settle with all defendants, and it will be a Nash equilibrium for all parties to settle.

(b) These results should be obvious from an inspection of equation (9).

(c) We can set (9) equal to 0 , and if we let $c_{p}=c_{d}=0$ and solve for $p_{d}$, then we find:

$$
p_{d}^{*}=\frac{1-\left(1-p_{p}\right)^{n}}{1+(N-1)\left(1-p_{p}\right)^{n}} .
$$

If we set $n=1$, then our results should be obvious from an inspection of (15).

(d) We can set (9) equal to 0 , and if we let $c_{p}=c_{d}=0$ and solve for $p_{p}$, then we find:

$$
p_{p}^{*}=1-\left(\frac{1-p_{d}}{1+p_{d}(N-1)}\right)^{\frac{1}{n}}
$$

If we set $n=1$, then our results should be obvious from an inspection of (16).

\section{Proof of Proposition 6:}

(a) Using equation (9), we can show that if $c_{d}=c_{p}=0, p_{d}=p_{p}=p$, and $n=N$, then $S<0$ if and only if:

$$
[(N-1) p+1](1-p)^{N-1}<1
$$

Note that if $N=1$, then both sides of (17) equal 1. Therefore, to prove inequality (17) holds for $N>1$, it will suffice to show that the left-hand side of (17) decreases in $N$. Taking the derivative of the left-hand side of (17) with respect to $N$ yields an expression that is negative 
if and only if:

$$
p<-[(N-1) p+1] \ln (1-p) .
$$

Given that the right-hand side of (18) is strictly increasing in $N$, it will be sufficient to show that (18) holds for $N=1$. That is, it will suffice to show that:

$$
p<-\ln (1-p) \text {. }
$$

To show that inequality (19) holds as long as $0<p<1$, first note that if $p=0$, then both sides of (19) equal 0 . Therefore, it will suffice to show that $-\ln (1-p)$ increases in $p$ at a faster rate than $p$. That is, taking the derivative of each side of (19) with respect to $p$, it is sufficient to show that:

$$
1<\frac{1}{1-p},
$$

which is obviously true as long as $0<p<1$.

(b) It should be obvious from an inspection of equation (9) that if $c_{d}=c_{p}=0, p_{d}=p_{p}=p$, and $n=N$, then $S(1)=0$ and $S(N)$ approaches 0 as $N$ goes to infinity. These results, together with result (a), imply that $S(N)$ must first fall and then rise as $N$ increases from 1 to infinity. To show that $S(N)$ has a unique local minimum, set $c_{d}=c_{p}=0, p_{d}=p_{p}=p$, and $n=N$ in equation (9), and then take the derivative of $S$ with respect to $N$. We can show that $S^{\prime}(N)=0$ if and only if:

$$
p=-[1+(N-1) p]^{2}(1-p)^{N-1} \ln (1-p)
$$

Using (19), we can show that at $N=1$, the right-hand side of (20) is greater than the left-hand side. Therefore, to show that equation (20) holds at a unique $N$, because the right-hand side of (20) is a continuous function of $N$, it will be sufficient to show that if the right-hand side of (20) is strictly decreasing at $N=x$, then it remains so for all $N>x$. Taking the derivative of the right-hand side of (20) with respect to $N$ yields an expression 
that is negative if and only if:

$$
2 p<-[1+(N-1) p] \ln (1-p)
$$

Given that the right-hand side of inequality (21) is strictly increasing in $N$, if inequality (21) holds for $N=x$, then it holds for any $N>x$. Therefore, $S^{\prime}(N)=0$ must occur at a unique $N$.

(c) Assume $c_{p}=c_{d}=0$, but suppose $p_{d}$ and $p_{p}$ can differ. If we set $n=N$, then (15) implies that:

$$
p_{d}^{*}=\frac{1-\left(1-p_{p}\right)^{N}}{N-(N-1)\left[1-\left(1-p_{p}\right)^{N}\right]} .
$$

It should be obvious from an inspection of $(22)$ that if $N=1$, then $p_{d}^{*}=p_{p}$ and that $p_{d}^{*}(N)$ approaches 1 as $N$ goes to infinity. To complete the proof, we must show that $p_{d}^{*}(N)$ increases monotonically in $N$.

To show that $p_{d}^{*^{\prime}}(N)>0$, take the derivative of $(22)$ with respect to $N$. The result is an expression that is positive if and only if:

$$
\left(1-p_{p}\right)^{N}-N \ln \left(1-p_{p}\right)>1
$$

Given (19), we know that inequality (23) holds for $N=1$. Therefore, to show $p_{d}^{*^{\prime}}(N)>0$ for all $N \geq 1$, it is sufficient to show that the left-hand side of (23) increases in $N$. Taking the derivative of the left-hand side of (23) with respect to $N$ yields:

$$
-\ln \left(1-p_{p}\right)\left[1-\left(1-p_{p}\right)^{N}\right]
$$

which is positive.

(d) Assume $c_{p}=c_{d}=0$, but suppose $p_{d}$ and $p_{p}$ can differ. If we set $n=N$, then (16) implies that:

$$
p_{p}^{*}=1-\left(\frac{1-p_{d}}{1+p_{d}(N-1)}\right)^{\frac{1}{N}}
$$


It should be obvious from an inspection of (24) that if $N=1$, then $p_{p}^{*}=p_{d}$. To complete the proof, we must show that $p_{p}^{*}(N)$ decreases in $N$ and approaches 0 as $N$ goes to infinity. Take the derivative of (24) with respect to $N$. The result is an expression that is negative if and only if:

$$
p_{d}<-\frac{1-p_{d}+N p_{d}}{N} \ln \frac{1-p_{d}}{1-p_{d}+N p_{d}} .
$$

Note that if $p_{d}=0$, then both sides of (25) equal 0 . Therefore, to show that inequality (25) holds for $0<p_{d}<1$, it is sufficient to show that the right-hand side of (25) increases in $p_{d}$ at a faster rate than the left-hand side. Taking the derivative of the right-hand side of (25) with respect to $p_{d}$ yields an expression that is greater than 1 if and only if:

$$
\frac{N p_{d}}{1-p_{d}}+(N-1) \ln \frac{1-p_{d}+N p_{d}}{1-p_{d}}>0
$$

which is obviously true for any $N \geq 1$. Therefore, $p_{p}^{*}$ declines monotonically in $N$.

To show that $p_{p}^{*}$ approaches 0 as $N$ goes to infinity, express equation (24) as follows:

$$
\left(1-p_{p}^{*}\right)^{N}\left[1+p_{d}(N-1)\right]=1-p_{d}
$$

It will be sufficient to show that for any $p_{p}^{*}$ between 0 and $p_{d}$, there exists an $N$ that solves (27), setting aside the integer constraint on $N$. For $p_{p}^{*}=p_{d}, N=1$ solves (27). For any smaller positive $p_{p}^{*}$, there exists an $N$ sufficiently large to solve (27). The left-hand side of equation (27) is the product of two functions of $N$. The first decreases in $N$; the second increases in $N$. Each unit increase in $N$ causes the first to fall by the same percentage but causes the second to increase by ever decreasing percentage. Thus, for any $p_{p}^{*}$ between 0 and $p_{d}$, a sufficiently large $N$ will cause the left-hand side of (27) fall, and we can always make the left-hand side as small as necessary to solve (27) by choosing a sufficiently large $N$. Therefore, we can make $p_{p}^{*}$ arbitrarily close to 0 by choosing a sufficiently large $N$. 


\section{Proof of Proposition 7:}

(a) If $n=N, p_{d}=p_{p}=p, c_{p}=0$, but $c_{d}>0$, then we know from (9) that:

$$
c_{d}^{*}=\left[1-(1-p)^{N}\right]\left[p+\frac{1-p}{N}\right]-p .
$$

It should be obvious from an inspection of equation (28) that if $N=1$, then $c_{d}^{*}=0$, and that $c_{d}^{*}$ approaches 0 as $N$ goes to infinity. Using (28), we can show that $c_{d}^{*}>0$ if and only if inequality (17) holds. Given that we have already shown that inequality (17) holds for any $N>1$, it follows that $c_{d}^{*}>0$ for any $N>1$.

To show that $c_{d}^{*}(N)$ has a unique local maximum, take the derivative of (28) with respect to $N$. We can show that $c_{d}^{*^{\prime}}(N)=0$ if and only if:

$$
(1-p)^{N}-N \ln (1-p)(1-p)^{N-1}[N p+1-p]=1 .
$$

Given (19), we can show that at $N=1$, the left-hand side of (29) is greater than the righthand side. Therefore, to show that equation (29) holds at a unique $N$, because the left-hand side of (29) is a continuous function of $N$, it will be sufficient to show that if the left-hand side of (29) is strictly decreasing at $N=x$, then it remains so for all $N>x$. Taking the derivative of the left-hand side of (29) with respect to $N$ yields an expression that is negative if and only if inequality (21) holds. We have already shown that if inequality (21) holds for $N=x$, then it holds for any $N>x$. Therefore, $c_{d}^{*^{\prime}}(N)=0$ must occur at a unique $N$.

(b) It should be obvious from an inspection of equation (9) that the expression for $S$ if $c_{p}=0$ is the same as the expression for $-c_{p}$ if $S=0$. Therefore, result (b) follows directly from the proofs of Proposition 6(a) and 6(b). 


\section{References}

[1] Dixon, Lloyd S., "The Transaction Costs Generated by Superfund's Liability Approach" in Richard L. Revesz and Richard B. Stewart, eds. Analyzing Superfund: Economics, Science, and Law (Washington, DC: Resources for the Future, 1995), pp. 171-185.

[2] Donohue, John J., III, "The Effect of Joint and Several Liability on the Settlement Rate - Mathematical Symmetries and Metaissues About Rational Litigant Behavior: Comment on Kornhauser and Revesz," Journal of Legal Studies 23 (1994), 543-558.

[3] Easterbrook, Frank H., William M. Landes, and Richard A. Posner, "Contribution Among Antitrust Defendants: A Legal and Economic Analysis," Journal of Law and Economics 23 (1980), 331-370.

[4] Eisenberg, Theodore and Henry S. Farber, "The Litigious Plaintiff Hypothesis: Case Selection and Resolution," RAND Journal of Economics 28 (1997), S92-S112.

[5] Guilkey, David K. and James L. Murphy, "Estimation and Testing in the Random Effects Probit Model," Journal of Econometrics 59 (1993), 301-317.

[6] Kahan, Marcel, "The Incentive Effects of Settlements under Joint and Several Liability," International Review of Law and Economics 16 (1996), 389-395.

[7] Kessler, Daniel, "Institutional Causes of Delay in the Settlement of Legal Disputes," Journal of Law, Economics, and Organization 12 (1996), 432-460.

[8] Kiefer, Nicholas M., "Economic Duration Data and Hazard Functions," Journal of Economic Literature 26 (1988), 646-679.

[9] Klerman, Daniel, "Settling Multidefendant Lawsuits: The Advantage of Conditional Setoff Rules," Journal of Legal Studies 25 (1996), 445-462.

[10] Kornhauser, Lewis A. and Richard L. Revesz, "Settlements Under Joint and Several Liability," New York University Law Review 68 (1993), 427-493.

[11] Kornhauser, Lewis A. and Richard L. Revesz, "Multidefendant Settlements: The Impact of Joint and Several Liability," Journal of Legal Studies 23 (1994), 41-76.

[12] Kornhauser, Lewis A. and Richard L. Revesz, "Evaluating the Effects of Alternative Superfund Liability Rules," in Richard L. Revesz and Richard B. Stewart, Analyzing Superfund: Economics Science and Law (Washington, DC: Resources for the Future, 1995a), pp. 115-144. 
[13] Kornhauser, Lewis A. and Richard L. Revesz, "De Minimis Settlements Under Superfund: An Empirical Study," in Richard L. Revesz and Richard B. Stewart, Analyzing Superfund: Economics Science and Law (Washington, DC: Resources for the Future, 1995b), pp. 187-215.

[14] Perloff, Jeffrey M. and Daniel L. Rubinfeld, "Settlements in Private Antitrust Litigation" in Lawrence J. White, ed. Private Antitrust Litigation (Cambridge, MA: M.I.T. Press, 1988), pp. 149-184.

[15] Polinsky, A. Mitchell, and Steven Shavell, "Contribution and Claim Reduction Among Antitrust Defendants: An Economic Analysis," Stanford Law Review 33 (1981), 447471.

[16] Reisch, Mark, Superfund Reauthorization Issues in the 105th Congress, Congressional Research Service Report, 1998.

[17] Spier, Kathryn E., "The Dynamics of Pretrial Negotiation," Review of Economic Studies 59 (1992), 93-108.

[18] Spier, Kathryn E., "A Note on Joint and Several Liability: Insolvency, Settlement, and Incentives," Journal of Legal Studies 23 (1994), 559-568.

[19] Tietenberg, Tom H., "Indivisible Toxic Torts: The Economics of Joint and Several Liability," Land Economics 65 (1989), 305-319.

[20] U.S. Enivornmental Protection Agency, Progress Toward Implementing Superfund, Fiscal Year 1994 (Washington, DC: The Agency, 1994).

[21] U.S. Environmental Protection Agency, Users Guide to the RPM Site Data, (Washington, DC: The Agency, 1995).

[22] Viscusi, W. Kip, "Determinants of the Disposition of Product Liability Claims and Compensation for Bodily Injury," Journal of Legal Studies 15 (1986), 321-346. 